\title{
Epithelial-to-mesenchymal transition leads to disease-stage differences in circulating tumor cell detection and metastasis in pre-clinical models of prostate cancer
}

\author{
Lori E. Lowes ${ }^{1}$, David Goodale ${ }^{3}$, Ying Xia ${ }^{3}$, Carl Postenka ${ }^{3}$, Matthew M. Piaseczny ${ }^{1}$, \\ Freeman Paczkowski ${ }^{3}$, Alison L. Allan ${ }^{1,2,3,4}$ \\ ${ }^{1}$ Department of Anatomy \& Cell Biology, Schulich School of Medicine and Dentistry, Western University, London ON, Canada \\ ${ }^{2}$ Department of Oncology, Schulich School of Medicine and Dentistry, Western University, London ON, Canada \\ ${ }^{3}$ London Regional Cancer Program, London Health Sciences Centre, London ON, Canada \\ ${ }^{4}$ Lawson Health Research Institute, London ON, Canada \\ Correspondence to: Alison L. Allan, email: alison.allan@lhsc.on.ca
}

Keywords: prostate cancer, circulating tumor cells, epithelial-to-mesenchymal transition, metastasis, pre-clinical models Received: July 14, $2016 \quad$ Accepted: September 29, $2016 \quad$ Published: October 15, 2016

\section{ABSTRACT}

Metastasis is the cause of most prostate cancer (PCa) deaths and has been associated with circulating tumor cells (CTCs). The presence of $\geq 5 \mathrm{CTCs} / 7.5 \mathrm{~mL}$ of blood is a poor prognosis indicator in metastatic PCa when assessed by the CellSearch ${ }^{\circledR}$ system, the "gold standard" clinical platform. However, 35\% of metastatic PCa patients assessed by CellSearch ${ }^{\circledR}$ have undetectable CTCs. We hypothesize that this is due to epithelial-to-mesenchymal transition (EMT) and subsequent loss of necessary CTC detection markers, with important implications for PCa metastasis. Two pre-clinical assays were developed to assess human CTCs in xenograft models; one comparable to CellSearch ${ }^{\circledR}$ (EpCAM-based) and one detecting CTCs semi-independent of EMT status via combined staining with EpCAM/HLA (human leukocyte antigen). In vivo differences in CTC generation, kinetics, metastasis and EMT status were determined using 4 PCa models with progressive epithelial (LNCaP, LNCaP-C42B) to mesenchymal (PC-3, PC-3M) phenotypes. Assay validation demonstrated that the CellSearch ${ }^{\circledR}$-based assay failed to detect a significant number $(\sim 40-50 \%)$ of mesenchymal CTCs. In vivo, PCa with an increasingly mesenchymal phenotype shed greater numbers of CTCs more quickly and with greater metastatic capacity than PCa with an epithelial phenotype. Notably, the CellSearch ${ }^{\circledR}$-based assay captured the majority of CTCs shed during early-stage disease in vivo, and only after establishment of metastases were a significant number of undetectable CTCs present. This study provides important insight into the influence of EMT on CTC generation and subsequent metastasis, and highlights that novel technologies aimed at capturing mesenchymal CTCs may only be useful in the setting of advanced metastatic disease.

\section{INTRODUCTION}

Prostate cancer $(\mathrm{PCa})$ is the most commonly diagnosed cancer and second most common cause of cancer death in American men [1]. The majority of prostate cancer deaths result from metastasis, since current therapies are non-curative in the metastatic setting [2]. Detection of circulating tumor cells (CTCs) in the blood is correlated with metastatic disease burden and reduced overall survival [3-6], with $\geq 5$ CTCs $/ 7.5 \mathrm{ml}$ of blood being indicative of poor prognosis in metastatic $\mathrm{PCa}$ patients [6]. Additionally, changes in CTC number throughout treatment have been demonstrated to reflect therapy response [7].

Due to the rare nature of CTCs $\left(\sim 1 \mathrm{CTC} / 10^{5}-10^{7}\right.$ leukocytes in metastatic patients), extremely sensitive technologies are required for accurate CTC detection [8]. Several techniques have been employed to enrich 
CTCs including size- and/or density-based separation, and antibody-based techniques with/without the aid of microfluidics, while detection techniques rely almost exclusively on protein- (immunofluorescence/flow cytometry) or nucleic acid-based (RT-PCR/qRT-PCR) assays $[9,10]$. Each approach has unique advantages and disadvantages; however most lack the standardization and quality control required for routine clinical use. The CellSearch $^{\circledR}$ system (CSS; Janssen Diagnostics) provides a standardized method for sensitive detection and quantification of CTCs in human blood. It is the only CTC assay approved by the U.S. Food and Drug Administration for clinical management of metastatic prostate, breast, and colon cancer patients [4-6], and is thus considered the "gold standard" CTC platform.

The CSS distinguishes CTCs from leukocytes through immunomagnetic selection of cells with an $\mathrm{EpCAM}^{+}$(epithelial cell adhesion molecule) phenotype followed by differential fluorescent staining for cytokeratins (CK) 8/18/19, CD45 (leukocyte marker), and DNA (4',6-diamidino-2-phenylindole [DAPI]). Although the CSS has been used to effectively enumerate CTCs in the blood of metastatic PCa patients [6], CTCs are undetectable in $\sim 30 \%$ of these patients despite the presence of systemic disease [11]. This suggests that either CTCs are truly not present in $\sim 1 / 3$ of metastatic PCa patients; or that CTCs are present but undetectable by the CSS because they do not meet the standard CTC definition $\left(\mathrm{EpCAM}^{+} / \mathrm{CK}^{+} / \mathrm{DAPI}^{+} / \mathrm{CD}^{-} 5^{-}\right)$. It has been proposed that this lack of detection may be due to the epithelialto-mesenchymal transition (EMT) [12-14], a dynamic cellular process that leads to downregulation of epithelial markers necessary for CTC capture/enumeration, including EpCAM/CK $[12,15,16]$. Corresponding increases in mesenchymal markers ( $\mathrm{N}$-cadherin/vimentin/ fibronectin) and resulting changes in cellular morphology have been shown to enhance cancer invasion, metastasis, therapy resistance, and disease aggressiveness [12, 17]. The standard CSS definition of CTCs may therefore be missing the most invasive and highly metastatic cells driving disease progression. In support of this, several studies have demonstrated that CTCs with a purely mesenchymal phenotype are undetectable by the CSS, but that the presence of mesenchymal marker expression on CTCs with a hybrid epithelial-mesenchymal (E-M) phenotype is indicative of poor prognosis [15, 18-21]. This suggests that current clinical CTC assays may be limiting our ability to capitalize on the full potential of CTCs, and that a greater understanding of CTC biology is necessary in order to guide future technology development and translation to the clinic.

The field of CTC research is quite unique in that it has evolved using a "bedside-to-bench" path rather than the more traditional "bench-to-bedside" model of translational research. Although this has allowed for quick entry of CTC technology into the clinic, outstanding questions regarding the biology of CTCs has resulted in a hesitance for their widespread adoption as biomarkers for directing patient care. Unfortunately, appropriate experimental tools needed to address these outstanding biology questions have been largely lacking, especially those that mimic the approach utilized by the clinicallyused CSS. This highlights the need for implementation of suitable pre-clinical models and development of complementary CTC analysis techniques that can assess not only the CTCs which are captured using the CSS but also those that may be missed, in order to advance knowledge. Previous work investigating CTC biology in our laboratory using orthotopic xenograft models demonstrated that CTC dissemination occurs relatively early in the metastatic cascade and that CTCs can be generated by both primary tumors as well as metastases [22-24]. However, very little is currently known about the functional role of EMT in CTC generation, detection and metastasis, particularly in the context of prostate cancer.

In this study, we hypothesized that the EpCAMbased CSS assay is unable to detect CTCs that have undergone EMT, and that EMT-related phenotypic differences in CTCs have important implications for PCa disease progression. To test this, we developed two preclinical assays for assessing human CTCs in xenograft models; one that is comparable to the EpCAM-based CSS (dependent on EMT status) and one that detects CTCs semi-independent of EMT status via negative depletion of CD45 and combined staining with EpCAM and HLA (human leukocyte antigen). Using these assays, differential in vivo CTC generation, capture efficiency, kinetics and metastasis were assessed using 4 human $\mathrm{PCa}$ cell lines (LNCaP, LNCaP C4-2B, PC-3, PC-3M) of increasing aggressiveness in pre-clinical orthotopic models of $\mathrm{PCa}$. The novel results presented here provide functional evidence of the interplay between EMT and CTC biology, shedding light on which CTCs are the most important to study. This knowledge has the potential to inform ongoing CTC technology development and guide strategies for the most effective use of CTCs as prognostic/predictive biomarkers in clinical oncology.

\section{RESULTS}

\section{Human PCa cell lines display differences in EMT phenotype}

Four human PCa cell lines (LNCaP, LNCaP C4-2B [C4-2B], PC-3, PC-3M) previously reported to have progressively increasing metastatic capacity [25-28] were characterized for epithelial (E-cadherin/EpCAM/ $\mathrm{CK})$ and mesenchymal (N-cadherin/vimentin) markers using qRT-PCR, immunoblotting (Supplementary Figure S1A, 1B), and flow cytometry (FCM) (Figure 1A). LNCaP and $\mathrm{C} 4-2 \mathrm{~B}$ had consistently higher protein expression of epithelial-associated markers E-cadherin and 
CK8/18/19, while PC-3 and PC-3M had consistently higher protein expression of mesenchymal-associated markers N-cadherin and vimentin. Although EpCAM levels appeared similar between cell lines at the mRNA level (Supplementary Figure S1A), differences in EpCAM protein expression were evident, with $\mathrm{LNCaP}$ and $\mathrm{C} 4-2 \mathrm{~B}$ demonstrating higher levels compared to PC-3 and PC3M (Supplementary Figure S1B, Figure 1A). To further
A
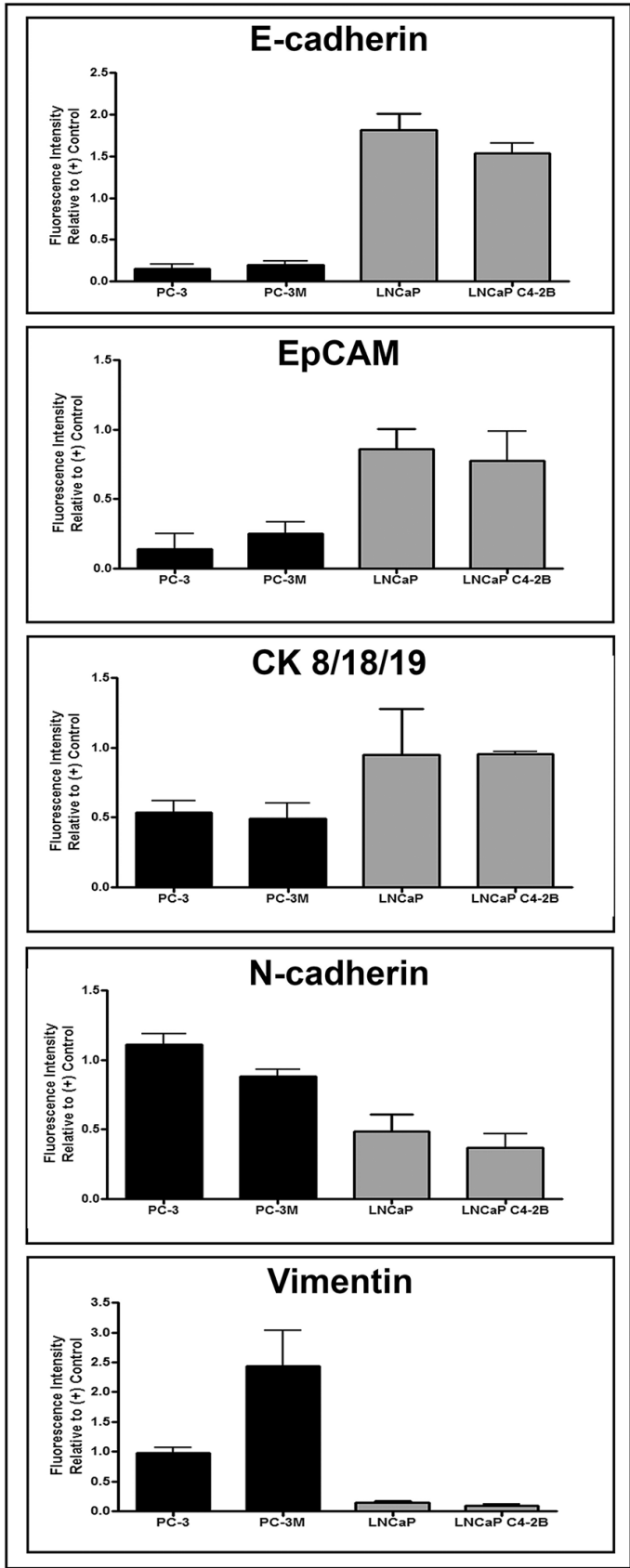

B

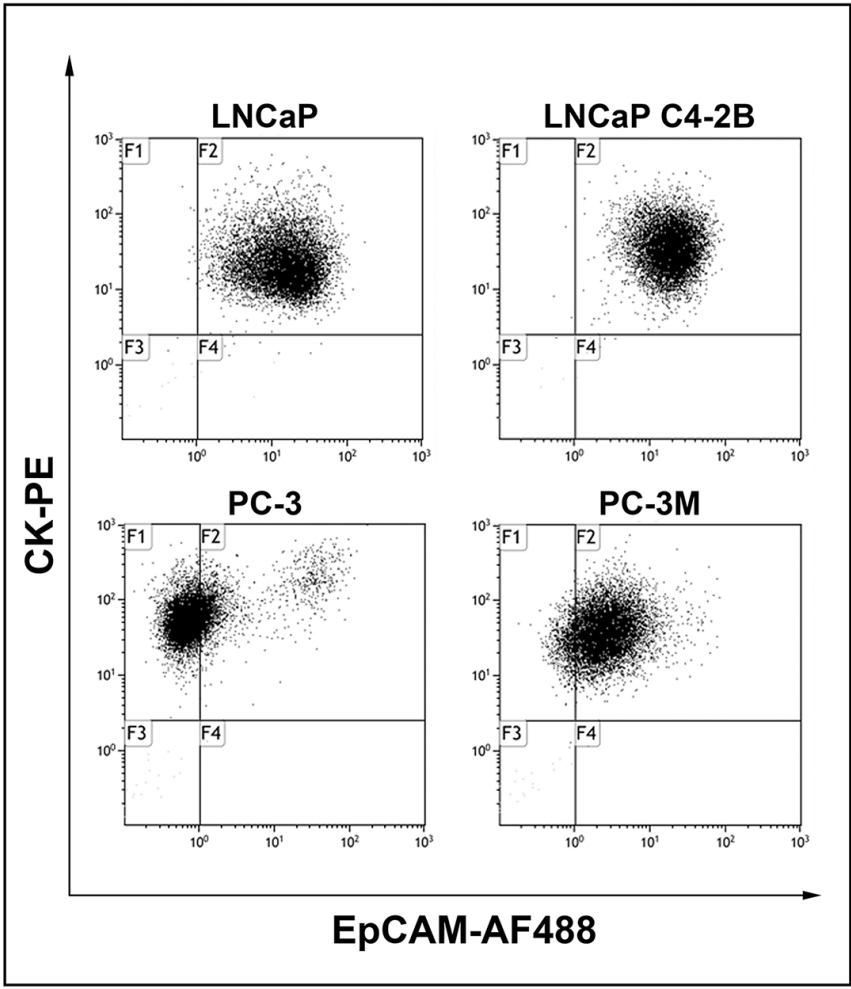

C

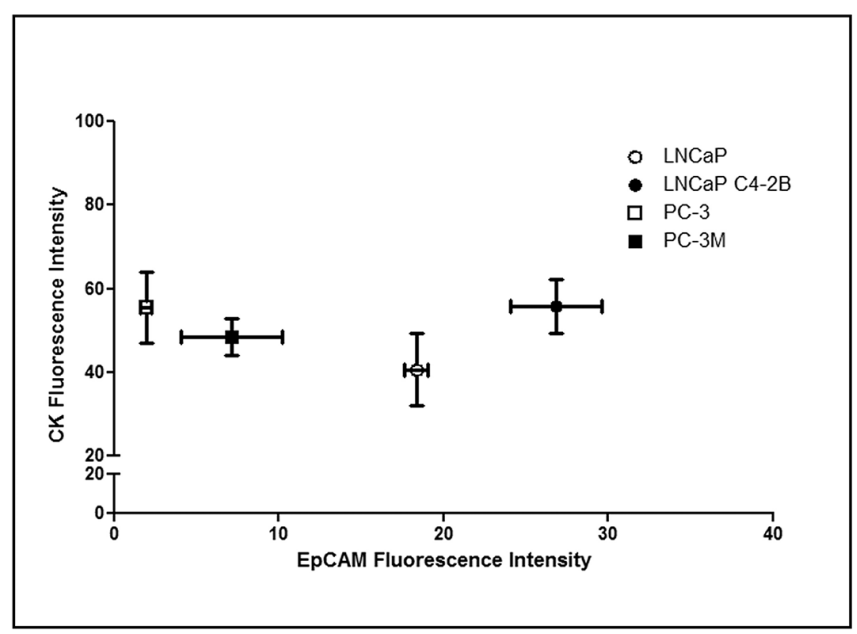

Figure 1: Human prostate cancer cell lines display differences in EMT phenotype. A. Protein expression analysis by flow cytometry for the epithelial-associated markers E-cadherin and EpCAM and the mesenchymal-associated markers N-cadherin and vimentin in PC-3M, PC-3, LNCaP C4-2B, and LNCaP human prostate cancer cells. Data are presented as relative fluorescence intensity (expression) compared to appropriate positive control cell lines (E-cadherin/EpCAM/CK: MDA-MB-468; N-cadherin/vimentin: HeLa) (n=3). The expression of epithelial-associated and mesenchymal-associated proteins corresponds to previously reported cell aggressiveness and in vivo metastatic capacity of these cell lines. B. Flow cytometry dot plots of the differential expression of EpCAM (AF488) and CK8/18/19 (PE) in investigated prostate cancer cell lines. C. Flow cytometry analysis for co-expression of EpCAM and CK8/18/19, presented as the mean \pm SEM fluorescence intensity of the investigated proteins for each cell line $(n=3)$. 
investigate potential capacity for capture of these cells by the EpCAM- and CK-reliant CSS, protein co-expression was assessed using FCM (Figure 1B, 1C). This further confirmed differential EpCAM expression between cell lines, but interestingly demonstrated a similar distribution of CK8/18/19 expression, suggesting that any differences in CTC capture between cell lines would be due to differences in EpCAM expression rather than CK8/18/19.

The ability of E-cadherin to maintain the epithelial phenotype and normal adhesive function of cells is dependent on its localization to the cell membrane $[29,30]$. We observed that that although E-cadherin was expressed in PC-3, it was aberrantly localized to the cytoplasm, likely due to a lack of $\alpha$-catenin expression which is necessary for appropriate E-cadherin membrane localization [31]. In contrast, LNCaP and C4-2B strongly expressed E-cadherin with appropriate membrane localization (Supplementary Figure S2).

\section{CTC recovery using the CSS is significantly reduced for PCa cells with a mesenchymal phenotype}

As the current gold standard CTC detection technology in the clinical setting, the CSS relies solely on the epithelial-associated marker EpCAM for CTC capture. However, EpCAM has been shown to be downregulated in cells with an invasive phenotype [32], suggesting that EpCAM-based CTC detection techniques such as the CSS may be missing a portion of the CTCs that enter the bloodstream. To assess this, we developed 2 novel preclinical CTC assays for use with xenograft models; one that recapitulates EpCAM-based capture of CTCs by the CSS ("EMT-dependent"), which captured CTCs based on an EpCAM+/CK+/CD45-/HLA+ phenotype, and one designed to detect all the CTCs shed into the circulation regardless of EMT status (“EMT semi-independent”), capturing CTCs based on a joint human HLA/EpCAM approach, including EpCAM ${ }^{\text {low/- }}$ cells (PC-3, PC-3M; likely captured primarily by HLA) and $\mathrm{EpCAM}^{+}$but $\mathrm{HLA}^{\text {variable/low }}$ cells (LNCaP, C4-2B; likely captured primarily by EpCAM). Use of the EMT-dependent assay resulted in significantly reduced recovery of CTCs with mesenchymal phenotypes (PC-3/PC-3M) when compared to CTCs with epithelial phenotypes (LNCaP/C4-2B) $(\mathrm{p} \leq 0.05)$ (Supplementary Figure S3A). However, when the EMT semi-independent assay was utilized, although overall CTC recovery was lower compared to the EMTdependent assay, percent recovery was not significantly different across cell lines regardless of EMT status (Supplementary Figure S3B). The reduced recovery demonstrated by the EMT semi-independent assay was further investigated by incorporating the additional sample handling steps required for the EMT semi-independent assay (i.e. red blood cell lysis and additional washes) into the EMT-dependent assay. The results demonstrated that when using the same reagents and highly epithelial cells (C4-2B), addition of extra processing steps resulted in equivalent sample loss between matched samples when comparing both assays (Supplementary Figure S3C).

\section{Prostate cancer cell lines with an increasingly mesenchymal phenotype have an enhanced capacity for CTC shedding in vivo and produce CTCs that are undetectable by the CSS}

LNCaP, C4-2B, PC-3, and PC-3M cells prepared in Hank's buffered saline were injected $\left(1 \times 10^{6}\right.$ cells $/ 40 \mu \mathrm{L}$ per mouse) orthotopically via the right dorsolateral lobe of the prostate as described in the Materials and Methods in order to assess in vivo CTC generation, kinetics, and detection by EMT-dependent versus EMT semi-independent assays, and relationship to subsequent metastasis. Using both CTC assays, we observed that highly mesenchymal PC-3M shed CTCs very quickly post-injection and in greater numbers than all other cell lines at most timepoints $(p \leq 0.05)$ (Figure 2A). Additionally, mesenchymal-like PC-3 shed a similar number of CTCs as epithelial $\mathrm{LNCaP}$ and $\mathrm{C} 4-$ 2B until week 4 (EMT semi-independent assay) or week 12 (EMT-dependent assay), at which time the number of CTCs increased significantly $(\mathrm{p} \leq 0.05)$. To quantify differences in CTC recovery based on EMT status, normalized CTC values obtained using both assays from each timepoint were generated, and numbers of CTCs identified using the EMT-dependent assay were subtracted from numbers of CTCs identified using the EMT semiindependent assay and presented as the mean for each timepoint. Positive values represent instances where more CTCs were detected with the EMT semi-independent assay, whereas negative values represent instances where more CTCs were detected with the EMT-dependent assay (Figure 2C). We observed that epithelial $\mathrm{LNCaP}$ and C4-2B had similar CTC recovery across both assays at all timepoints investigated. However, mesenchymal PC-3 and PC-3M showed increased numbers of CTCs recovered using the EMT semi-independent assay at later timepoints, with significant differences observed when comparing PC-3 to LNCaP and C4-2B at 12 weeks $(\mathrm{p} \leq 0.05)$.

\section{Prostate cancer cell lines with an increasingly mesenchymal phenotype have enhanced capacity for primary tumor formation and metastasis}

To determine differences in the extent of disease and metastatic spread across the 4 cells lines, at necropsy, animals were assessed for primary tumor incidence/ weight, and metastatic spread to lymph nodes and distant metastatic sites (lung, liver, bone). We observed that primary tumor incidence and size was significantly increased in highly mesenchymal PC-3M compared to all other cell lines $(\mathrm{p} \leq 0.05)$, except when considering tumor weight of PC-3 at 2 weeks (Figure 3A, 3B). All other cell 
A

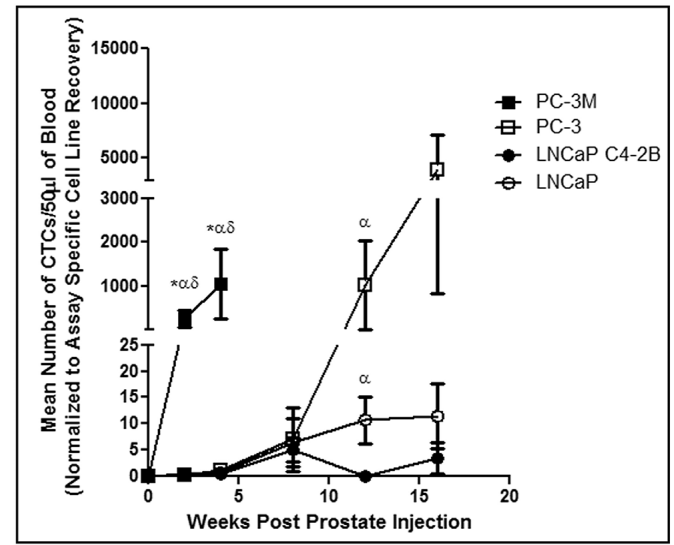

B

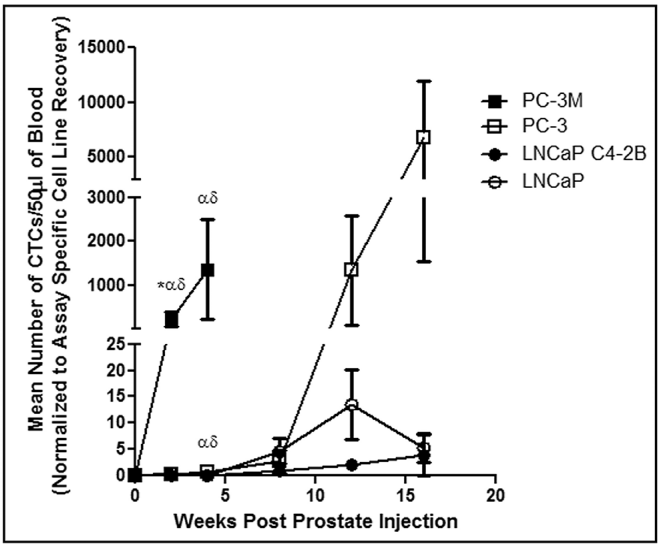

C

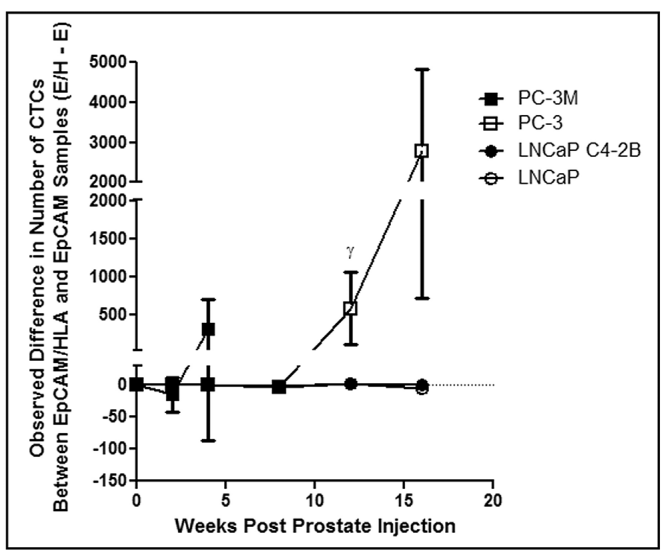

Figure 2: Human prostate cancer cell lines with an increasingly mesenchymal phenotype shed greater numbers of CTCs more quickly and have an enhanced in vivo capacity for shedding CTCs that are undetectable by the CellSearch ${ }^{\circledR}$ system. PC-3M, PC-3, LNCaP C4-2B, and LNCaP human prostate cancer cells were orthotopically injected into 6-8 week old male nude mice via the right dorsolateral lobe of the prostate $\left(1 \times 10^{6}\right.$ cells/mouse $)$ to assess spontaneous metastasis. At several timepoints post injection $(2,4,8,12$, and 16 weeks) mice were sacrificed and blood $(100 \mu \mathrm{l})$ was collected and processed using both the A. EMT-dependent and $\mathbf{B}$. EMT semi-independent assays (50 $\mathrm{\mu l} /$ assay) to assess differences in CTC recovery. Data are presented as the mean $\pm \mathrm{SEM}(\mathrm{n}=5-12$ mice/ group). C. Comparison of the observed difference in the number of CTCs detected using the EMT-dependent and EMT semi-independent assays in matched samples. Data are presented as the mean ( \pm SEM) difference in the number of observed CTCs between both assays (\# captured by EpCAM/HLA assay - \# captured by EpCAM assay) at a given timepoint ( $\mathrm{n}=5-12$ mice/group). Positive values represent groups in which more CTCs were detected with the EMT semi-independent assay, whereas negative values represent groups in which more CTCs were detected with the EMT-dependent assay. Differences in the mean number of CTCs between cell lines at a given timepoint using and differences between each assay within individual mice was assessed using Wilcoxon Scores followed by a Kruskal-Wallis test at each timepoint. Comparison of differences between each assay in matched data sets within cell lines at a given timepoint was performed using a Wilcoxon matched-pairs signed rank test. * = significant difference relative to PC-3; $\alpha=$ significant difference relative to LNCaP C4-2B; $\delta$ $=$ significant difference relative to $\mathrm{LNCaP} ; \gamma=$ overall significant difference (unable to perform pairwise comparison) $(\mathrm{p} \leq 0.05)$. 
lines showed comparable primary tumor incidence and weight at all timepoints. Additionally, primary tumor weight and the number of CTCs shed into the circulation (EMT-semi-independent assay) were positively correlated for all cell lines (Figure 3C). Immunohistochemical analysis of E-cadherin/N-cadherin revealed that all cell lines demonstrated comparable epithelial/mesenchymal phenotypes in vivo relative to those seen in vitro (Figure 3D, Supplementary Figure S4A).

A

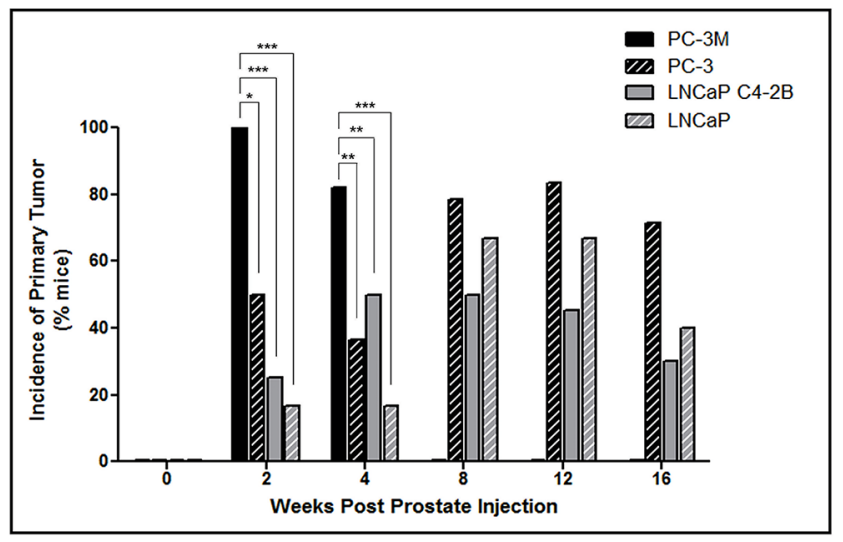

C
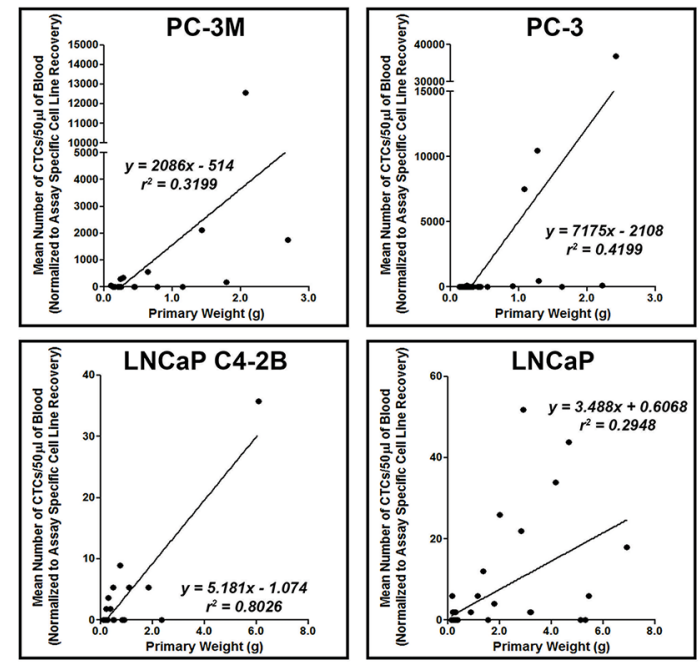

H\&E
Additional differences between mesenchymal and epithelial cell lines were observed in metastatic incidence (\% of mice developing metastasis) and metastatic burden (\% of organ occupied by metastatic tumor) to the lymph nodes (LN). Microscopy analysis revealed that PC-3M had significantly increased incidence of LN metastases versus all other cell lines at 4 weeks $(p \leq 0.05)$, while PC-3 had significantly increased incidence at 8 and 12 weeks compared to $\mathrm{C} 4-2 \mathrm{~B}(\mathrm{p} \leq 0.05)$. Interestingly, the incidence

B

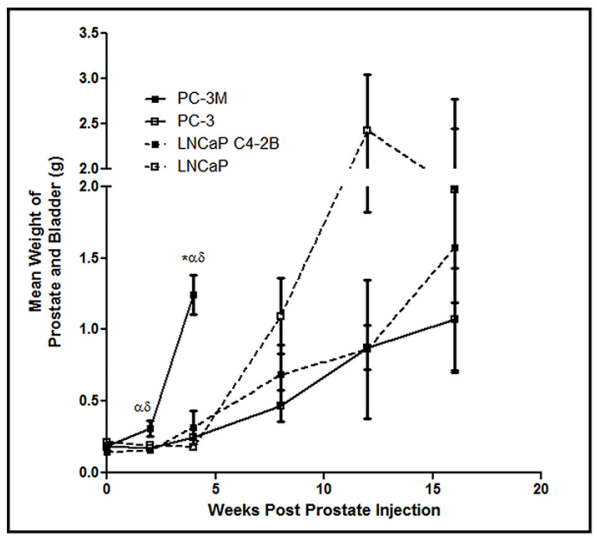

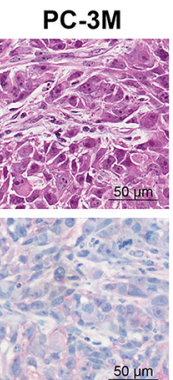
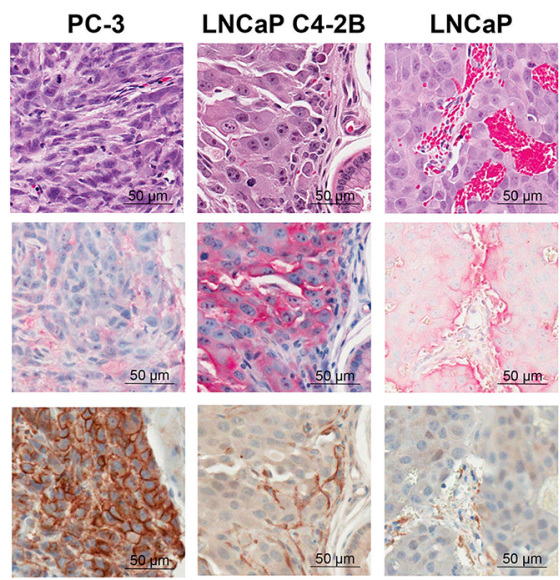

Figure 3: Highly mesenchymal prostate cancer cells exhibit enhanced primary tumor incidence and size and in all cell lines CTC number is correlated with primary tumor size. A. Incidence of primary tumor formation following orthotopic injection of PC-3M, PC-3, LNCaP C4-2B, and LNCaP human prostate cancer cell lines. Data are presented as the percentage of mice per cell line per timepoint with detectable primary tumors ( $\mathrm{n}=6-39 \mathrm{mice} /$ group) as assessed by microscopic histological examination of formalin-fixed, H\&E stained tissue. ${ }^{*}=$ significantly different $(\mathrm{p}<0.05), * *(\mathrm{p}<0.01), * * *(\mathrm{p}<0.001)$. B. Mean combined weight of prostate and bladder at time of sacrifice following orthotopic injection of prostate cancer cell lines. Data are presented as the mean \pm SEM ( $\mathrm{n}=6-39 \mathrm{mice} / \mathrm{group}$ ). C. Mean normalized number of CTCs $/ 50 \mu 1$ of blood (assessed using the EMT semi-independent assay) correlates with the primary tumor weight in all cell lines. D. Representative H\&E and IHC (E-cadherin and N-cadherin) images of primary prostate tumors for each cell line $(40 \mathrm{x}$; scale bars $=50 \mu \mathrm{m})$. Primary tumor weights were assessed for cell line variances using Levene's test, followed by a 1-way ANOVA with Tukey's post-test for multiple comparisons. Spearman rank correlation was utilized to examine the relationship between mean number of CTCs and primary tumor weight. ${ }^{*}=$ significant difference relative to $\mathrm{PC}-3 ; \alpha=$ significant difference relative to LNCaP C4-2B; $\delta=$ significant difference relative to $\mathrm{LNCaP}(\mathrm{p} \leq 0.05)$. 
of metastases to $\mathrm{LN}$ did not differ significantly between PC-3 and LNCaP (Supplementary Figure S5A). However, PC-3 did demonstrate significantly increased metastatic burden compared to $\mathrm{C} 4-2 \mathrm{~B}$ at 8 and 12 weeks $(\mathrm{p} \leq 0.05)$ (Supplementary Figure S5B). Therefore, although these cell lines appear to have a similar capacity to disseminate to LN, they do not have the same capacity for subsequent growth in this organ. Finally, LNCaP demonstrated significantly increased metastatic burden compared to C4$2 \mathrm{~B}$ at 12 weeks $(\mathrm{p} \leq 0.05)$. Representative $\mathrm{H} \& \mathrm{E}$ and $\mathrm{IHC}$ analysis of LN metastases are shown in Supplementary Figure S4B, S5C.

Differences in distant metastasis were investigated by gross assessment at necropsy and microscopic assessment following $\mathrm{H} \& \mathrm{E}$ staining. We observed that both PC-3M and PC-3 could disseminate to and establish gross macrometastases in a number of distant organs, while no visible macrometastases were observed at necropsy in mice injected with either LNCaP or C4-2B (Figure 4). However, microscopy analysis of lung and liver revealed distant metastases to these organs for all of the investigated cell lines. Analysis of the incidence of gross metastatic disease demonstrated that more mesenchymal PC-3M and PC-3 had significantly increased metastatic capacity versus more epithelial LNCaP and C4$2 \mathrm{~B}(\mathrm{p} \leq 0.05)$ (Figure 5A). Representative H\&E and IHC analysis of lung metastases are shown in Figure 5B and Supplementary Figure S4C. Additionally, the number of CTCs was significantly higher across all cell lines in mice with metastatic disease relative to those without $(\mathrm{p} \leq 0.05)$ (Figure 5C), and in those cell lines with the greatest metastatic capacity, thus demonstrating the relationship between CTCs and metastatic spread.

\section{Circulating tumor cells acquire a more mesenchymal phenotype during disease progression}

To further investigate the EMT profile of CTCs shed into the circulation, blood was used to generate CTC sub-lines representing different timepoints along the metastatic cascade. Briefly, excess blood, not required for CTC assessment, was lysed $\left(\mathrm{NH}_{4} \mathrm{Cl}\right)$, washed, and resuspended in cell line specific culture medium. Cells were cultured, with frequent media changes to remove contaminating white blood cells, and subsequently assessed for EMT marker expression using immunoblotting. Unfortunately due to low numbers of CTCs collected from LNCaP and C4-2B, CTC growth following plating did not occur. However several sub-lines were created for both PC-3 and PC3M. Immunoblot analysis (Figure 6) demonstrated a significant reduction in E-cadherin expression in CTCs collected at all timepoints compared to the parental PC-3 $(\mathrm{p} \leq 0.05)$, a trend in reduction of EpCAM expression, a significant increase in $\mathrm{N}$-cadherin expression at later timepoints $(\mathrm{p} \leq 0.05)$, and a trend towards increasing vimentin expression, suggesting CTCs may become more mesenchymal as disease progresses.

\section{DISCUSSION}

CTCs have emerged as a promising biomarker for tracking disease progression and therapy response in patients with different types of solid tumors. However, although CTCs are now used clinically for prognostication in metastatic prostate, breast and colorectal cancer, their underlying biology and the complex interplay between EMT, CTCs and metastasis remains poorly understood. Therefore significant debate remains with regards to which CTCs are the most valuable to capture and characterize, and which will serve as optimal tools for personalized cancer treatment [33]. The lack of knowledge about CTC biology stems from both the unique bedside-to-bench approach employed in the CTC field and the lack of appropriate tools for studying CTCs in vivo in pre-clinical metastasis models.

This study aimed to address these gaps through development of two novel pre-clinical CTC enumeration assays and their implementation for determining differences in CTC detection using an epithelial-based (EMT-dependent) method and a human versus mousebased (EMT semi-independent) approach to assess the generation of mesenchymal CTCs that would be missed by current technologies, particularly the clinically used CSS. Although a previous experimental study examined CTCs in mouse models using pre-engineered, fluorescentexpressing PC-3 PCa cells [34], this is not a clinicallyrelevant scenario and thus we instead aimed to assess CTCs using assays modeled after those used clinically. By leveraging the capabilities of the existing CSS clinical platform and taking advantage of the HLA complex in separating human from mouse cells, the assays described here are the first report of adaptation of the CSS for use in xenograft models, without mis-identification of mouse epithelial cells. In addition, these assays allow for the processing/analysis very low volumes of blood $(50 \mu \mathrm{l})$, making these assays amenable to both blood collected at necropsy as well as serial monitoring of xenograft models in which less than $100 \mu \mathrm{l}$ aliquots of blood can be typically collected.

In the current study, assay validation using sensitivity/recovery studies demonstrated that the CSSbased assay failed to detect a significant number ( 40$50 \%$ ) of mesenchymal CTCs. In vivo, PCa tumors with an increasingly mesenchymal phenotype shed greater numbers of CTCs more quickly and with greater metastatic capacity than those with an epithelial phenotype. Notably, the CSSbased assay captured the majority of CTCs shed during earlystage disease regardless of EMT status of the originating tumor, and only after the establishment of metastases were a significant number of undetectable mesenchymal CTCs 
Gross Metastases

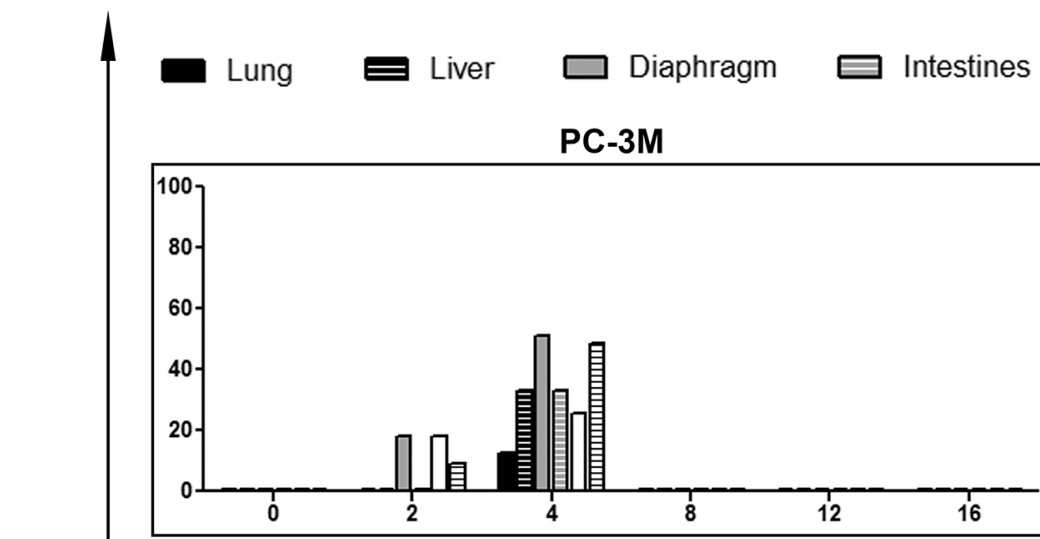

PC-3

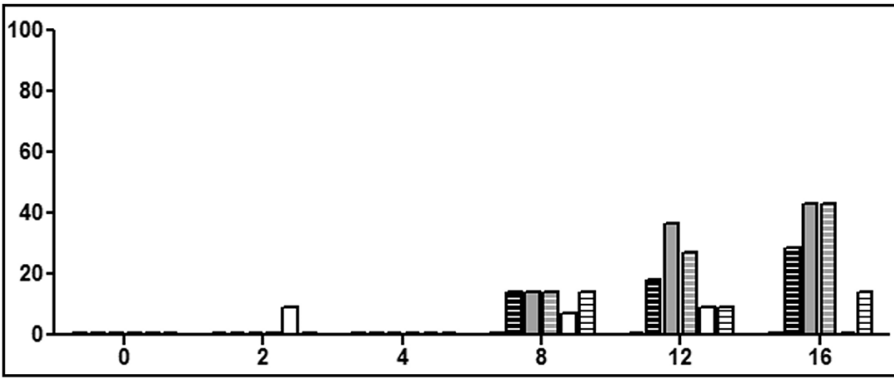

LNCaP C4-2B

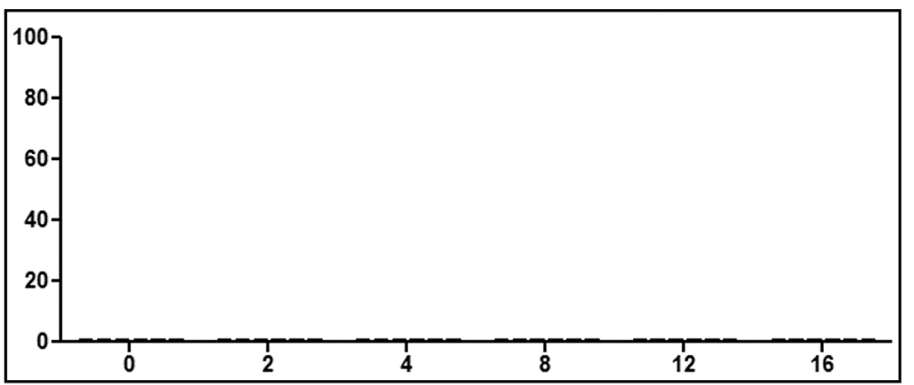

LNCaP

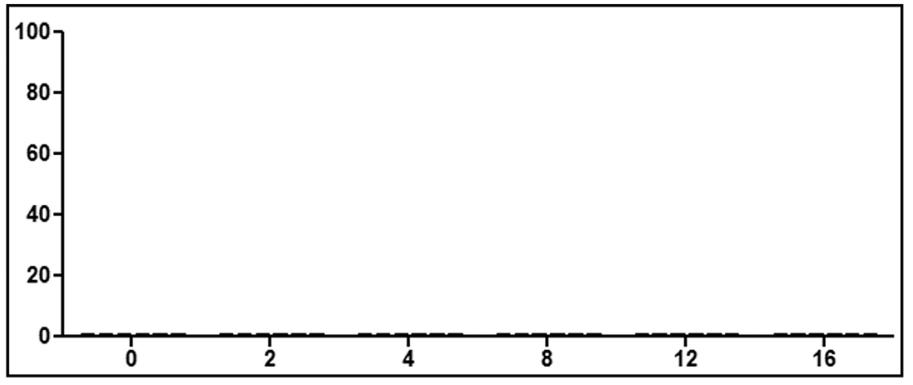

Microscopic Metastases

Kidney

Spleen/Pancreas

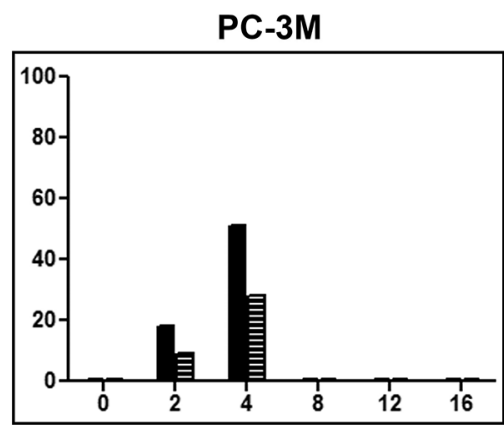

PC-3

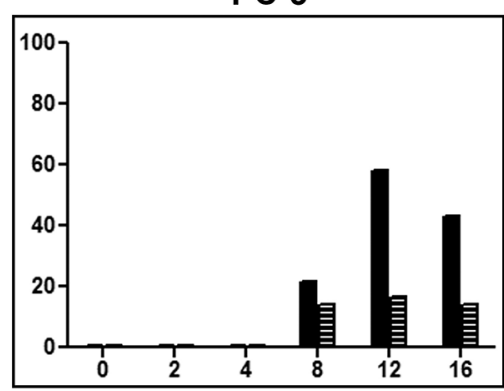

LNCaP C4-2B

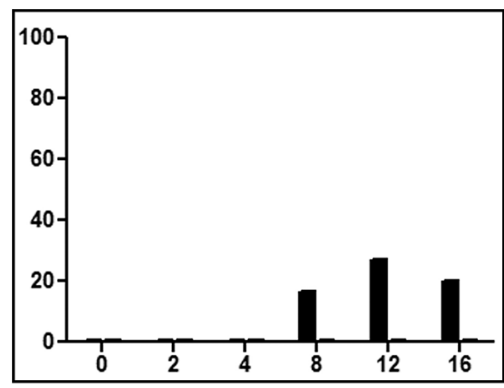

LNCaP

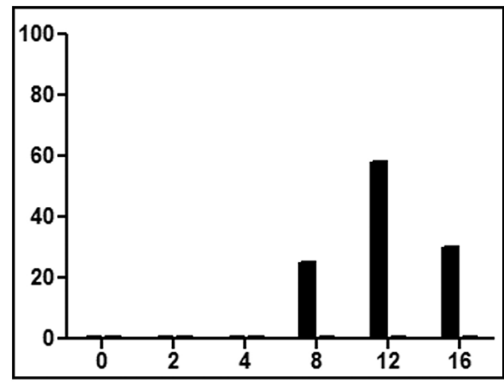

\section{Weeks Post Prostate Injection}

Figure 4: Human prostate cancer cell lines with an increasingly mesenchymal phenotype have an enhanced in vivo capacity for metastasis to distant organs. Incidence of metastasis to distant organs following orthotopic injection of PC-3M, PC-3, LNCaP C4-2B, and LNCaP human prostate cancer cell lines. Data are presented as the percentage of mice per cell line per timepoint with detectable distant metastases to the lung, liver diaphragm, intestines, kidney, and/or spleen/pancreas ( $\mathrm{n}=7-39$ mice/group) as assessed by gross observation at necropsy (left panel) and microscopic histological examination (right panel) of tissues. 
A

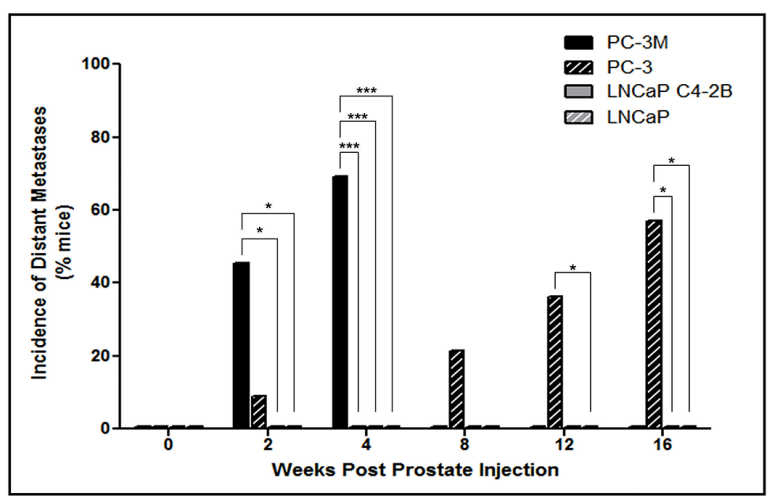

B

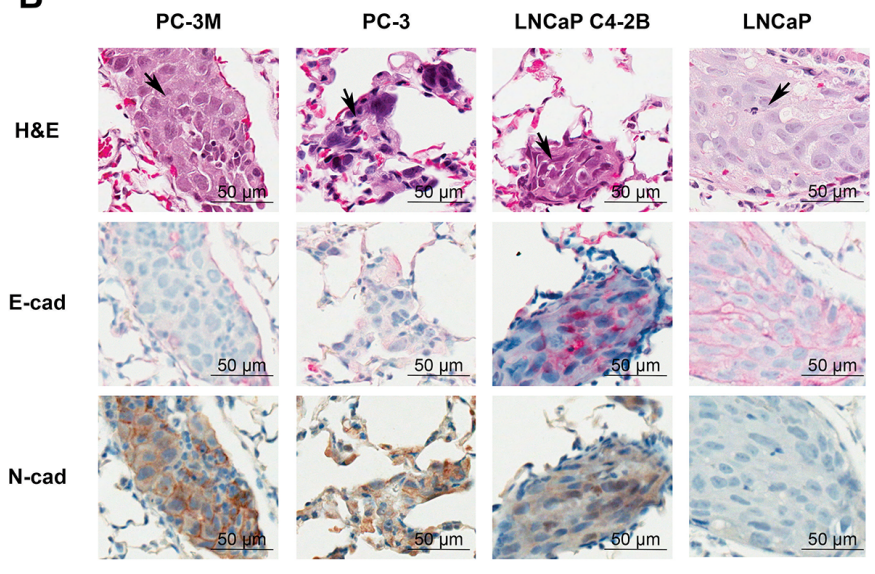

C
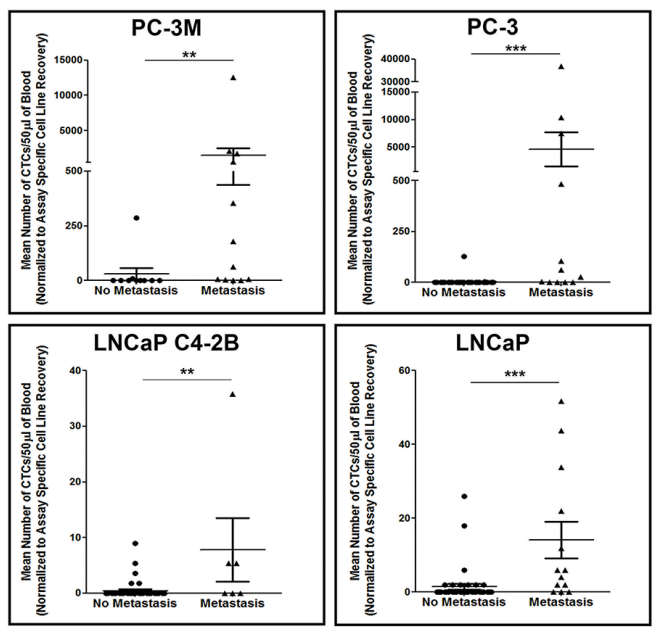

Figure 5: Mesenchymal human prostate cancer cell lines exhibit an enhanced capacity for metastasis that is correlated with CTC dissemination. A. Incidence of metastasis to distant organs following orthotopic injection of PC-3M, PC-3, LNCaP C42B, and LNCaP prostate cancer cell lines. Data are presented as the percentage of mice per cell line per timepoint with detectable distant metastases ( $\mathrm{n}=7-39$ mice/group) as assessed by gross observation at necropsy. B. Representative H\&E and IHC (E-cadherin and N-cadherin) images of lung metastases for each investigated cell line. Histological sections are presented at 40x magnification. Arrowheads on H\&E images indicate regions of tumor within the given tissue. Scale bars $=50 \mu \mathrm{m}$. C. Correlation of CTC number and incidence of metastasis. Mean number of CTCs $/ 50 \mu 1$ of blood, assessed using the EMT semi-independent assay, are presented for mice with either metastasis to the lymph nodes or any distant organ (based on gross and/or microscopic analysis) or mice with no evidence of metastasis at any timepoint ( $\mathrm{n}=6-47$ mice/group). Differences in the incidence of primary tumors, lymph node metastasis, and distant metastasis were assessed using Fisher's Exact Test. Differences in the mean number of CTCs in mice with no metastasis versus those with metastatic disease were compared using a Student's t-test. ${ }^{*}=$ significantly different $(\mathrm{p} \leq 0.05),{ }^{* *}(\mathrm{p}<0.01),{ }^{* * *}(\mathrm{p}<0.001)$. 
present. It is important to note that the EMT semi-independent assay, although novel and innovative, is unfortunately not adaptable for use with human blood samples. However, significant effort is being focused on the development of CTC capture techniques capable of recovering not only CTCs expressing epithelial markers (EpCAM/CK), but also

\section{E-cadherin}

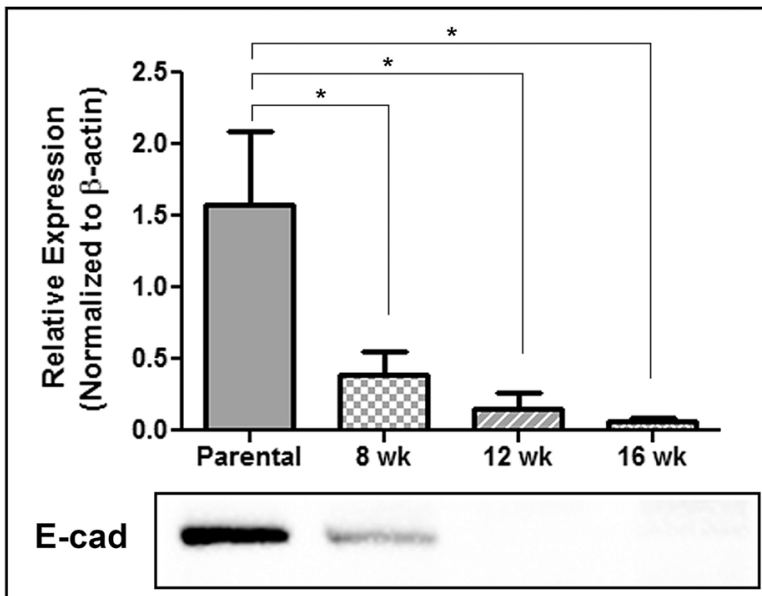

Actin

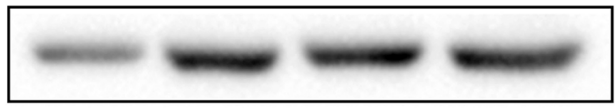

(or even instead) those with a highly mesenchymal phenotype $[9,10]$ in human specimens. This latter pursuit is based on the idea that mesenchymal CTCs are the "bad actors"; a hypothesis supported by experimental studies demonstrating that EMT imparts enhanced invasiveness, metastatic capacity, and therapy resistance [9, 10, 12]. Efforts to detect

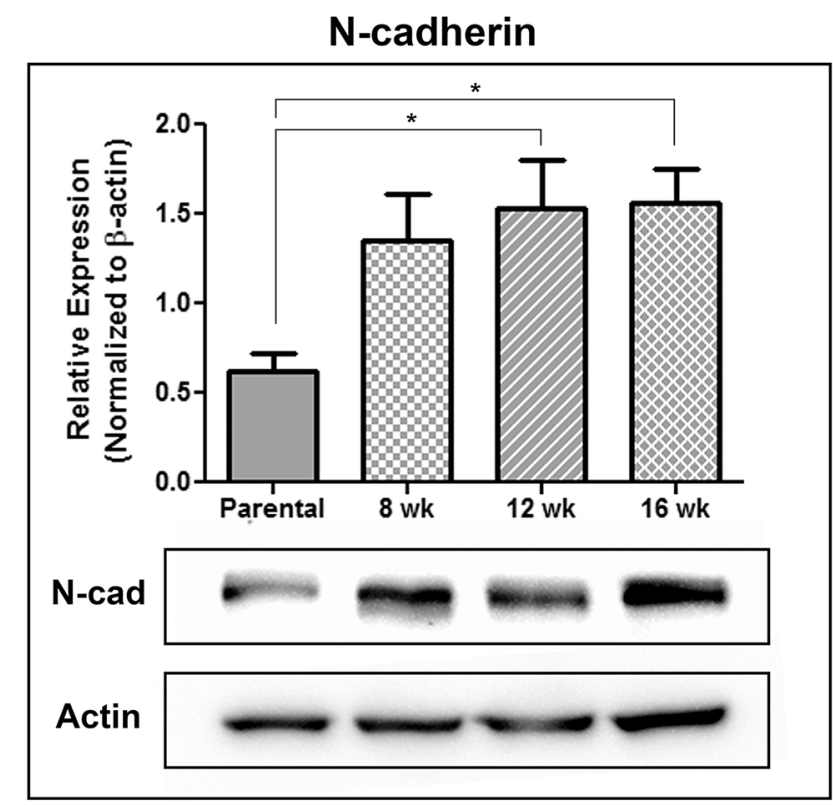

EpCAM

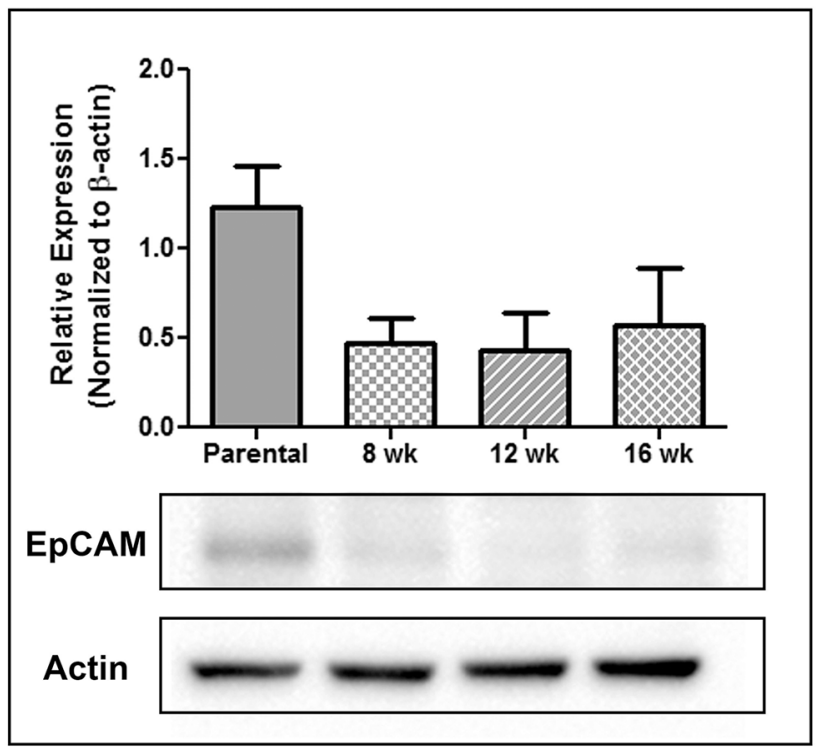

Vimentin

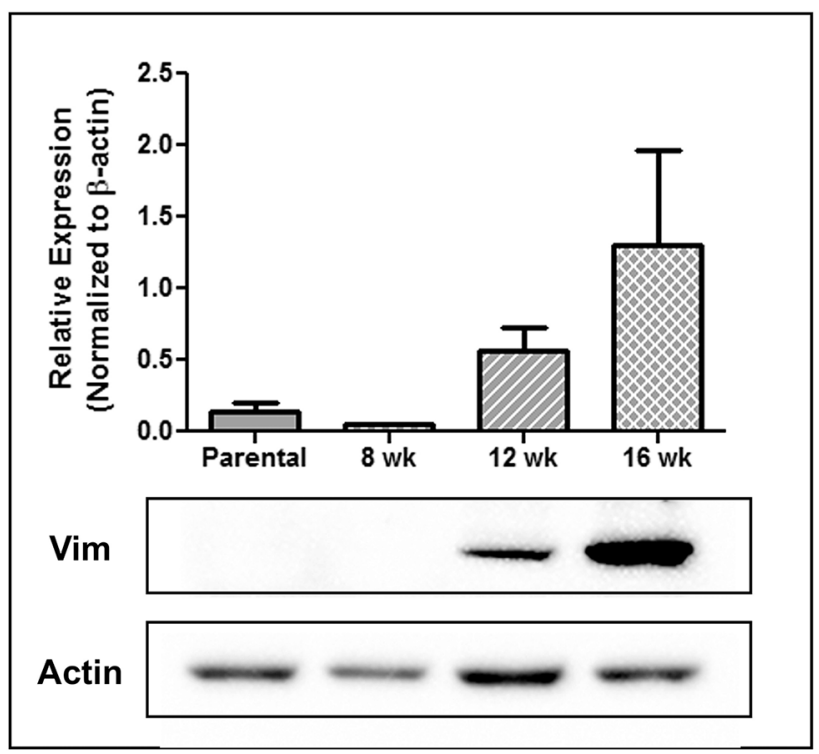

Figure 6: Circulating tumor cells acquire a more mesenchymal phenotype during disease progression. Following orthotopic injection of PC-3 prostate cancer cells into the right dorsolateral lobe of the prostate $\left(1 \times 10^{6}\right.$ cells $/$ mouse $)$ blood collected at 8 weeks, 12 weeks, and 16 weeks post-injection was lysed with sterile $1 \mathrm{x} \mathrm{NH}_{4} \mathrm{Cl}$, washed with PBS, and plated for tissue culture. Following 1-2 weeks of growth, with regular media changes to remove contaminating blood cells, the remaining CTCs were assessed using immunoblot for the expression of the epithelial-associated markers E-cadherin and EpCAM and the mesenchymal-associated markers N-cadherin and vimentin. Results are presented in quantitative densitometric form normalized to $\beta$-actin and as representative immunoblots, shown as cropped gel images $(n=3)$. Changes in EMT gene expression were compared to the parental cell line using 1-way ANOVA with Dunnett's post-test for multiple comparisons. $*=$ significantly different than parental line $(\mathrm{p} \leq 0.05)$. 
these "bad actors" have included the exploitation of various properties of CTCs that are either independent or less reliant on their EMT status (e.g., size/deformability [microfiltration/ microfluidics], electrical properties [dielectrophoresis], immunomagenetic approaches using organ/tumor specificantigens [carcinoembyronic antigen (CEA), epidermal growth factor receptor (EGFR), prostate specific antigen (PSA), mucin-1 (MUC-1)], and adhesion assays based on CTCs ability to adhere to the presented capture surface) [35]. However, our results demonstrate that although prostate tumors with mesenchymal phenotypes shed CTCs earlier and in greater numbers than those with epithelial phenotypes, the majority these CTCs are still captured by the CSS, at least before the establishment of metastatic disease. This indicates that CTCs shed early in disease may have a hybrid EMT phenotype during dissemination, while still expressing sufficient levels of EpCAM and CK8/18/19 for detection using epithelial-based techniques. Therefore, CTCs with an E-M hybrid (rather than purely mesenchymal) phenotype may be important for establishing metastasis and therefore most interesting to characterize, at least in earlystage patients. This is supported by observations that CTCs with a hybrid phenotype may be of particular importance in the clinical setting based on their EMT/MET phenotypic plasticity [19].

Our data further demonstrates a significant increase in the number of mesenchymal CTCs that are undetectable by the CSS following the establishment of distant metastases. This increase in mesenchymal characteristics of CTCs in late-stage disease has also been demonstrated in patients with metastatic versus localized disease [36, 37]. However, further studies are needed to determine if/ how these undetectable CTCs are contributing to disease progression and metastasis. This is because, despite widespread speculation, there is little evidence to support the hypothesis that highly mesenchymal CTCs have any additional prognostic/predictive value compared to hybrid E-M or even purely epithelial CTCs in patients. However, we must consider that technological limitations related to mesenchymal CTC capture may significantly hinder testing of this hypothesis in the clinic. In addition, we cannot rule out the possibility that highly mesenchymal CTCs are present in early-stage disease but not in high enough numbers to significantly contribute to differences between the 2 CTC assays described. In fact, the cancer stem cell (CSC) hypothesis posits that only a fraction of cells within the primary tumor efficiently complete the metastatic process [38]. Therefore it is possible that the dramatic increase in mesenchymal CTCs following the development of metastases is due to selective outgrowth of CSCs [39]. Thus, although this study provides valuable insights into the role of EMT in CTC dissemination/ kinetics, many questions remain, for which the assays developed here will be very useful in answering.

In addition to this study's contributions towards understanding CTC biology and its relationship to EMT, to our knowledge it is the first comprehensive head-to-head comparison of EMT characteristics and in vivo behavior (including CTC dissemination/kinetics) of 4 commonly used PCa cell lines using orthotopic injection models of PCa. It is important to note that the metastatic process may differ in in vivo spontaneous metastasis models in comparison to the actual disease setting in a patient (e.g., differences in the antigen expression/tissue architecture impacting intravasation/extravasation, and decreased immunesurveillance in immune-compromised models) and therefore the selection of appropriate metastasis models which best recapitulate disease progression and dissemination is an important consideration [40-42]. The orthotopic model utilized throughout this study provides a much more clinically relevant model of CTC production and metastasis than more commonly used (and technically less challenging) subcutaneous injection models [34]. Based upon this careful selection, we anticipate that the data presented here will serve as a valuable tool for future PCa research.

Overall, our pre-clinical studies provide important translational information that will inform the use of CTCs as valuable biomarkers of cancer progression in the clinic. In particular, our data highlights that how CTC capture/ characterization is utilized in the clinic may greatly depend on disease stage. Specifically, in early-stage patients where CTCs could provide tremendous value for predicting metastasis (i.e. adjuvant setting), detection of an increased number of CTCs may not require technology designed to capture mesenchymal CTCs, but instead processing of additional blood $(>7.5 \mathrm{~mL})$ on epithelial-based CTC technologies (e.g., CSS) may suffice $[43,44]$. In addition, our data supports the idea that primary tumors with an increasingly mesenchymal phenotype may have enhanced metastatic capacity and therefore the detection of CTCs with a hybrid E-M phenotype may be of prognostic/ predictive importance in early-stage patients. In contrast, in late-stage disease we have demonstrated a significant increase in undetectable and highly mesenchymal CTCs after the establishment of distant metastasis. Therefore further research in this patient cohort will need to examine the functional role of these CTCs versus those with an epithelial or hybrid phenotype in disease progression and, importantly, in therapy resistance. Taken together, the results presented here provide novel and important insight into the functional influence of EMT on CTC generation and metastasis in PCa. Ultimately a better understanding of CTC biology will aid in identifying CTCs that will be most valuable for determining individualized treatment of metastatic cancer.

\section{MATERIALS AND METHODS}

\section{Cell culture}

LNCaP [45] (ATCC, Manassas, VA) and PC3M [46] (a gift from Paula Foster, Western University, London, $\mathrm{ON}$ ) human PCa cells were maintained in RPMI$1640+10 \%$ fetal bovine serum (FBS). LNCaP C4-2B [47] 
[C4-2B] human PCa cells (a gift from Katherine Stemke Hale, M.D. Anderson, Houston, TX) were maintained in T-media $+10 \%$ FBS. PC-3 human PCa cells [48] (ATCC) were maintained in F12K media+10\%FBS. MDA-MB-468 human breast cancer cells [49] (a gift from Janet Price, M.D. Anderson) were maintained in $\alpha \mathrm{MEM}+10 \% \mathrm{FBS}$. HeLa human cervical cancer cells [50] (a gift from Jim Koropatnick, Western University) were maintained in DMEM+10\%FBS. Media/reagents and FBS were obtained from Life Technologies (Carlsbad, CA) and Sigma (St. Louis, MO), respectively. Cell lines were authenticated via third-party testing (CellCheck, IDEXX BioResearch, Columbia, MO) in December 2015.

\section{Real-time PCR}

RNA was isolated using TRIzol (Life Technologies), reverse-transcribed and subjected to quantitative reversetranscription polymerase chain reactions (qRT-PCR) using Brilliant II SYBR Green qPCR Master Mix (Agilent Technologies, Santa Clara, CA) on a Stratagene Mx3000P (Life Technologies) (primer/cycling details; Supplementary Table S1). Samples were normalized using pooled qPCR human reference total RNA (Agilent Technologies) [51].

\section{Immunoblotting}

Cells were harvested by cell scraping (E-cadherin, $\mathrm{N}$-cadherin) or trypsinization (vimentin, EpCAM, $\alpha$-catenin) and collected in 1\% NP-40 lysis buffer. Protein $(10 \mu \mathrm{g})$ was subjected to sodium dodecyl sulfate polyacrylamide gel electrophoresis (SDS-PAGE) and transferred onto polyvinylidene difluoride membranes (PVDF; Millipore, Billerica, MA). Membranes were blocked $(5 \%$ skim milk in TBS-T [Tris-buffered saline $+0.1 \%$ Tween-20]; Sigma). Primary antibodies, diluted in 5\% skim milk in TBS-T are described Supplementary Table S2. Goat-anti-mouse-IgG and goat-anti-rabbit-IgG secondary antibodies (Calbiochem, Billerica, MA) conjugated to horseradish peroxidase and diluted in 5\% skim milk in TBS-T were used at 1:2,000 for all proteins except E-cadherin (1:10,000). Protein expression was visualized using Amersham ECL Prime Detection Reagent (GE Healthcare, Wauwatosa, WI), and normalized to total protein based on amido black (Sigma) membrane staining.

\section{Flow cytometry}

Cells $\left(5 \times 10^{5}\right)$ were treated with the IntraPrep ${ }^{\mathrm{TM}} \mathrm{Fix} /$ Perm kit (Beckman Coulter, Fullerton, CA, USA) and incubated with blocking buffer (PBS/5\% BSA [bovine serum albumin]); 15min). Cells were incubated with primary antibodies (30min) as detailed in Supplementary Table S3, followed by incubation with AlexaFluor488conjugated goat-anti-mouse IgG or AlexaFluor488- conjugated goat-anti-rabbit IgG secondary antibodies (1 $\mu \mathrm{g}$; Life Technologies). Samples were analyzed using an EPICS XL-MCL or Cytomics FC500 flow cytometer (Beckman Coulter).

\section{Immunofluorescence}

Cells were seeded into glass chamber slides (Thermo Scientific) pre-coated with fibronectin $(5 \mu \mathrm{g} / \mathrm{mL}$; Santa Cruz Biotechnologies, Dallas, TX), grown until confluent, fixed with $2 \%$ paraformaldehyde, permeabilized (0.1\% Triton X-100; Sigma) and blocked (PBS/1\% BSA; $1 \mathrm{hr}$ ) prior to incubation with anti-E-cadherin and/or anti- $\alpha$ catenin primary antibodies $(1: 50 ; 1 \mathrm{hr})$. Cells were labeled with goat-anti-mouse-IgG-AlexaFluor488 and/or goatanti-rabbit-IgG-AlexaFluor594 (Life Technologies; 1:300; $1 \mathrm{hr}$ ) before mounting with VectaShield+DAPI (Vector Laboratories, Burlingame, CA). Imaging was performed (60x) using an Olympus Provis AX70 microscope (Olympus, Richmond Hill, ON).

\section{Pre-clinical CTC assay development}

Whole blood $(100 \mu \mathrm{L}$ minimum) was collected from 6-8wk old male athymic nude $(\mathrm{nu} / \mathrm{nu})$ mice (Harlan Sprague-Dawley, Indianapolis, IN) via cardiac puncture as described $[22,23]$. Blood was processed immediately or stored for up to 48 hours with an equal volume of CytoChex (Streck, Omaha, NE). For CTC assay development, $50 \mu \mathrm{L}$ of blood was "spiked" with 1000 tumor cells. To assess recovery of low numbers of cells (5-100), serial dilutions were performed (data not shown).

The EMT-dependent CTC assay was adapted from the Veridex mouse/rat CellCapture kit (no longer available) as described previously [52]. Briefly, $50 \mu \mathrm{L}$ of whole blood was incubated with components of the CellSearch $^{\circledR}$ CTC kit; including anti-EpCAM ferrofluid, Capture Enhancement Reagent, Nucleic Acid Dye, Staining Reagent, and Permeabilization Reagent. Additional reagents included anti-mouse-CD45-APC

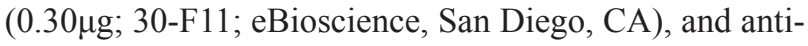

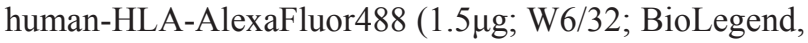
San Diego, CA). Samples were immune-magnetically separated and transferred to a MagNest ${ }^{\mathrm{TM}}$ for analysis using the CSS. EpCAM ${ }^{+} / \mathrm{CK}^{+} / \mathrm{DAPI}^{+} / \mathrm{CD} 45 / \mathrm{HLA}^{+}$cells with a round/oval morphology were classified as CTCs.

Development of the EMT semi-independent CTC assay was based on negative selection/immunodepletion of CD45 ${ }^{+}$leukocytes combined with dual staining with human HLA and EpCAM. Our initial assay design only employed HLA (to take advantage of the human-in-mouse model), however we observed that relative levels of HLA present on each of the cell lines was highly variable, and in particular the $\mathrm{EpCAM}^{+} \mathrm{LNCaP}$ and $\mathrm{C} 4-2 \mathrm{~B}$ cells had low HLA compared to PC3 cells (data not shown). Since differences in HLA would makes interpretation of CTC capture data 
very difficult, we took a joint HLA/EpCAM approach which detects all CTCs present, including $\mathrm{EpCAM}^{\text {low/- }}$ cells (PC-3, PC-3M; by HLA) and EpCAM ${ }^{+}$but HLA Eariable/low $^{\text {ve }}$ cells (LNCaP, C4-2B; by EpCAM). For testing, $50 \mu \mathrm{L}$ of blood was lysed with $\mathrm{NH}_{4} \mathrm{Cl}$. Samples were washed and labeled (20min) using anti-human-HLA-PE (0.2 $\mu \mathrm{g}$; W6/32; BioLegend), anti-human-EpCAM-PE (0.0075 $\mu \mathrm{g}$; EBA-1; BD Bioscience), and anti-mouse-CD45-APC (0.30 $\mu \mathrm{g})$. Samples were washed and immunomagnetically enriched using the EasySep APC Positive Selection kit (StemCell Technologies, Vancouver, BC). The tumor cell fraction was incubated (20min) in Permeabilization Reagent $(100 \mu \mathrm{L})$ and Nucleic Acid Dye (50 $\mathrm{LL}$; Janssen Diagnostics). After washing, cells bound by PE-conjugated antibodies (HLA/ EpCAM) were immunomagnetically labelled using the EasySep PE Positive Selection kit (StemCell Technologies) and transferred to a MagNest ${ }^{\mathrm{TM}}$ for analysis using the CSS. EpCAM/HLA ${ }^{+} / \mathrm{DAPI}^{+} / \mathrm{CD} 45^{-}$cells with a round/oval morphology were classified as CTCs.

\section{In vivo $\mathrm{CTC}$ and metastasis assays}

Animal experiments were conducted under protocol\# 2012-031 approved by Western University's Animal Care Committee. PCa cells were prepared in sterile Hank's buffered saline (Life Technologies) and injected $\left(1 \times 10^{6}\right.$ cells $/ 40 \mu \mathrm{L}$ per mouse) orthotopically into $6-8 \mathrm{wk}$ old male athymic nude ( $n u / n u$ ) mice (Harlan Sprague-Dawley) via the right dorsolateral lobe of the prostate as described $[53,54]$. Briefly, a low midline abdominal incision of approximately 3-4 mm was made in anesthetized mice. The bladder was gently lifted and the right dorsolateral lobe was identified. The cell solution was slowly injected into the prostate gland before replacing the bladder and suturing the muscle and skin layers closed. At 2,4,8,12 and 16wks post-injection, mice were sacrificed, necropsies performed, and tissues collected. Prostates and bladders were weighed as surrogates of primary tumor volume. Blood $(100 \mu \mathrm{L})$ was collected and processed using both CTC assays $(50 \mu \mathrm{L} /$ assay) to assess differences in CTC dissemination and kinetics. Whenever possible, CTC sub-cell lines were generated using excess blood lysed $\left(\mathrm{NH}_{4} \mathrm{Cl}\right)$ and cultured.

Throughout the study mice were occasionally sacrificed at modified timepoints $( \pm 1-2 w k s)$ due to morbidity and/or technical issues. To facilitate statistical analysis, mice were categorized based on time of sacrifice (1-3, 4-6, 8-10, $11-13$ or $14-16 \mathrm{wks})$. For simplicity, data is presented at the initially defined timepoints $(2,4,8,12,16 \mathrm{wks})$. Due to unexpectedly rapid progression of the $\mathrm{PC}-3 \mathrm{M}$ cell line, CTCs in this group could only be assessed at 2-4wks.

\section{Histology and immunohistochemistry}

At necropsy, tissues were formalin-fixed, paraffinembedded, sectioned $(4 \mu \mathrm{m})$ and stained (hematoxylin and eosin $[\mathrm{H} \& \mathrm{E}])$. Serial sections were deparaffinized (xylene) and rehydrated (graded series of alcohols $[100 / 95 / 80 / 75 \%])$ prior to staining. Antigen retrieval was performed ( $10 \mathrm{mM}$ sodium citrate buffer $/ 0.05 \%$ Tween-20 $\left.\left[100^{\circ} \mathrm{C} ; 20 \mathrm{~min}\right]\right)$ before incubation with BLOXALL Endogenous Peroxidase and Alkaline Phosphatase Blocking Solution (Vector Laboratories). Staining for E-cadherin (1:100) and N-cadherin (1:750) was performed (Polink DS-MR-Hu kit [GBI Labs, Bothell, WA]). Slides were imaged (40x) using an Aperio ScanScope (Aperio Technologies, Vista CA).

\section{Statistical analysis}

Statistical analysis was performed using GraphPad Prism 5.0 (San Diego, CA) and/or SPSS (IBM, Armonk, $\mathrm{NY}$ ) as detailed in Figure Legends, with $\mathrm{p} \leq 0.05$ considered statistically significant.

\section{ACKNOWEDGMENTS}

The authors would like to thank Benjamin Hedley and Michael Keeney for their help and advice with CTC assay development and flow cytometry analysis; Madeleine Moussa for her advice with the pathohistologic analysis; and Larry Stitt for his assistance with statistical data analysis.

\section{CONFLICTS OF INTEREST}

A.L.A. has been the recipient of investigatorinitiated research support from Janssen Diagnostics and Janssen Oncology (Canada) for clinical studies unrelated to the pre-clinical study reported in this manuscript. All other authors have no potential conflicts to declare.

\section{GRANT SUPPORT}

Funding for this study was provided by a grant from Prostate Cancer Canada (to A.L.A.). L.E.L. and M.M.P. were supported by graduate scholarships from the Canadian Institutes for Health Research (CIHR). A.L.A. was supported by a CIHR New Investigator Award and an Early Researcher Award from the Ontario Ministry of Research and Innovation.

\section{REFERENCES}

1. Siegel RL, Miller KD, Jemal A. Cancer statistics, 2016. CA Cancer J Clin. 2016; 66: 7-30.

2. Chambers AF, Groom AC, MacDonald IC. Dissemination and growth of cancer cells in metastatic sites. Nat Rev Cancer. 2002; 2: 563-572.

3. Pantel K, Brakenhoff RH, Brandt B. Detection, clinical relevance and specific biological properties of disseminating tumour cells. Nat Rev Cancer. 2008; 8: 329-340. 
4. Cristofanilli M, Budd GT, Ellis MJ, Stopeck A, Matera J, Miller MC, Reuben JM, Doyle G V, Allard WJ, Terstappen LWMM, Hayes DF. Circulating tumor cells, disease progression, and survival in metastatic breast cancer. $\mathrm{N}$ Engl J Med. 2004; 351: 781-791.

5. Cohen SJ, Punt CJ a, Iannotti N, Saidman BH, Sabbath KD, Gabrail NY, Picus J, Morse M a, Mitchell E, Miller MC, Doyle G V, Tissing H, Terstappen LWMM, et al. Prognostic significance of circulating tumor cells in patients with metastatic colorectal cancer. Ann Oncol. 2009; 20: 1223-1229.

6. de Bono JS, Scher HI, Montgomery RB, Parker C, Miller MC, Tissing H, Doyle G V, Terstappen LWWM, Pienta KJ, Raghavan D. Circulating tumor cells predict survival benefit from treatment in metastatic castration-resistant prostate cancer. Clin Cancer Res. 2008; 14: 6302-6309.

7. Goldkorn A, Ely B, Quinn DI, Tangen CM, Fink LM, Xu T, Twardowski P, Van Veldhuizen PJ, Agarwal N, Carducci MA, Monk JP, Datar RH, Garzotto M, et al. Circulating tumor cell counts are prognostic of overall survival in SWOG S0421: a phase III trial of docetaxel with or without atrasentan for metastatic castration-resistant prostate cancer. J Clin Oncol. 2014; 32: 1136-1142.

8. Allan AL, Keeney M. Circulating tumor cell analysis: technical and statistical considerations for application to the clinic. J Oncol. 2010; 2010: 426218.

9. Lowes LE, Allan AL. Recent advances in the molecular characterization of circulating tumor cells. Cancers (Basel). 2014; 6: 595-624.

10. Ferreira MM, Ramani VC, Jeffrey SS. Circulating tumor cell technologies. Mol Oncol. 2016; 10: 374-394.

11. Allard WJ, Matera J, Miller MC, Repollet M, Connelly MC, Rao C, Tibbe AGJ, Uhr JW, Terstappen LWMM. Tumor cells circulate in the peripheral blood of all major carcinomas but not in healthy subjects or patients with nonmalignant diseases. Clin Cancer Res. 2004; 10: 6897-6904.

12. Thiery JP, Acloque H, Huang RYJ, Nieto MA. Epithelialmesenchymal transitions in development and disease. Cell. 2009; 139: 871-890.

13. Joosse SA, Gorges TM, Pantel K. Biology, detection, and clinical implications of circulating tumor cells. EMBO Mol Med. 2015; 7: 1-11.

14. Jolly MK, Boareto M, Huang B, Jia D, Lu M, Ben-Jacob E, Onuchic JN, Levine H. Implications of the Hybrid Epithelial/Mesenchymal Phenotype in Metastasis. Front Oncol. 2015; 5: 155.

15. Gorges TM, Tinhofer I, Drosch M, Röse L, Zollner TM, Krahn T, von Ahsen O. Circulating tumour cells escape from EpCAM-based detection due to epithelial-tomesenchymal transition. BMC Cancer. 2012; 12: 178.

16. Santisteban M, Reiman JM, Asiedu MK, Behrens MD, Nassar A, Kalli KR, Haluska P, Ingle JN, Hartmann LC, Manjili MH, Radisky DC, Ferrone S, Knutson KL. Immune-induced epithelial to mesenchymal transition in vivo generates breast cancer stem cells. Cancer Res. 2009; 69: 2887-2895.

17. Yang J, Weinberg R a. Epithelial-mesenchymal transition: at the crossroads of development and tumor metastasis. Dev Cell. 2008; 14: 818-829.

18. Yu M, Bardia A, Wittner BS, Stott SL, Smas ME, Ting DT, Isakoff SJ, Ciciliano JC, Wells MN, Shah AM, Concannon KF, Donaldson MC, Sequist L V, et al. Circulating breast tumor cells exhibit dynamic changes in epithelial and mesenchymal composition. Science. 2013; 339: 580-584.

19. Armstrong AJ, Marengo MS, Oltean S, Kemeny G, Bitting RL, Turnbull JD, Herold CI, Marcom PK, George DJ, Garcia-Blanco $\mathrm{M}$ a. Circulating tumor cells from patients with advanced prostate and breast cancer display both epithelial and mesenchymal markers. Mol Cancer Res. 2011; 9: 997-1007.

20. Bulfoni M, Gerratana L, Del Ben F, Marzinotto S, Sorrentino M, Turetta M, Scoles G, Toffoletto B, Isola M, Beltrami CA, Di Loreto C, Beltrami AP, Puglisi F, et al. In patients with metastatic breast cancer the identification of circulating tumor cells in epithelial-to-mesenchymal transition is associated with a poor prognosis. Breast Cancer Res. 2016; 18: 30.

21. Lindsay CR, Le Moulec S, Billiot F, Loriot Y, Ngo-Camus M, Vielh P, Fizazi K, Massard C, Farace F. Vimentin and Ki67 expression in circulating tumour cells derived from castrateresistant prostate cancer. BMC Cancer. 2016; 16: 168.

22. Goodale D, Phay C, Postenka CO, Keeney M, Allan AL. Characterization of tumor cell dissemination patterns in preclinical models of cancer metastasis using flow cytometry and laser scanning cytometry. Cytometry A. 2009; 75: 344-355.

23. Allan AL, Vantyghem S a, Tuck AB, Chambers AF, Chin-Yee $\mathrm{IH}$, Keeney M. Detection and quantification of circulating tumor cells in mouse models of human breast cancer using immunomagnetic enrichment and multiparameter flow cytometry. Cytometry A. 2005; 65: 4-14.

24. Lowes LE, Goodale D, Keeney M, Allan AL. Image cytometry analysis of circulating tumor cells. Methods Cell Biol. 2011; 102: 261-290.

25. Stephenson RA, Dinney CP, Gohji K, Ordóñez NG, Killion JJ, Fidler IJ. Metastatic model for human prostate cancer using orthotopic implantation in nude mice. J Natl Cancer Inst. 1992; 84: 951-957.

26. Shah G V., Thomas S, Muralidharan A, Liu Y, Hermonat PL, Williams J, Chaudhary J. Calcitonin promotes in vivo metastasis of prostate cancer cells by altering cell signaling, adhesion, and inflammatory pathways. Endocr Relat Cancer. 2008; 15: 953-964.

27. Fu Z, Smith PC, Zhang L, Rubin MA, Dunn RL, Yao Z, Keller ET. Effects of raf kinase inhibitor protein expression on suppression of prostate cancer metastasis. J Natl Cancer Inst. 2003; 95: 878-889. 
28. Pettaway CA, Pathak S, Greene G, Ramirez E, Wilson MR, Killion JJ, Fidler IJ. Selection of Highly Metastatic Variants of Different Human Prostatic Carcinomas Using Orthotopic Implantation in Nude Mice. Clin Cancer Res. 1996; 2: 1627-1636.

29. Nagafuchi A, Takeichi M. Cell binding function of E-cadherin is regulated by the cytoplasmic domain. EMBO J. 1988; 7: 3679-3684.

30. Ozawa M, Ringwald M, Kemler R. Uvomorulin-catenin complex formation is regulated by a specific domain in the cytoplasmic region of the cell adhesion molecule. Proc Natl Acad Sci U S A. 1990; 87: 4246-4250.

31. Morton RA, Ewing CM, Nagafuchi A, Tsukita S, Isaacs WB. Reduction of E-cadherin levels and deletion of the alpha-catenin gene in human prostate cancer cells. Cancer Res. 1993; 53: 3585-3590.

32. Gosens MJEM, van Kempen LCL, van de Velde CJH, van Krieken JHJM, Nagtegaal ID. Loss of membranous Ep-CAM in budding colorectal carcinoma cells. Mod Pathol. 2007; 20: 221-232.

33. Yap TA, Lorente D, Omlin A, Olmos D, de Bono JS. Circulating tumor cells: a multifunctional biomarker. Clin Cancer Res [Internet]. 2014; 20: 2553-2568.

34. Glinskii AB, Smith BA, Jiang P, Li X-M, Yang M, Hoffman RM, Glinsky G V. Viable circulating metastatic cells produced in orthotopic but not ectopic prostate cancer models. Cancer Res. 2003; 63: 4239-4243.

35. Gabriel MT, Calleja LR, Chalopin A, Ory B, Heymann D. Circulating Tumor Cells: A Review of Non-EpCAM-Based Approaches for Cell Enrichment and Isolation. Clin Chem. 2016; 62: 571-581.

36. Papadaki MA, Kallergi G, Zafeiriou Z, Manouras L, Theodoropoulos PA, Mavroudis D, Georgoulias V, Agelaki S. Co-expression of putative stemness and epithelial-tomesenchymal transition markers on single circulating tumour cells from patients with early and metastatic breast cancer. BMC Cancer. 2014; 14: 1-10.

37. Kallergi G, Papadaki MA, Politaki E, Mavroudis D, Georgoulias V, Agelaki S. Epithelial to mesenchymal transition markers expressed in circulating tumour cells of early and metastatic breast cancer patients. Breast Cancer Research. 2011. p. R59.

38. Croker AK, Allan AL. Cancer stem cells: implications for the progression and treatment of metastatic disease. J Cell Mol Med. 2008; 12: 374-390.

39. Baccelli I, Schneeweiss A, Riethdorf S, Stenzinger A, Schillert A, Vogel V, Klein C, Saini M, Bäuerle T, Wallwiener M, Holland-Letz T, Höfner T, Sprick M, et al. Identification of a population of blood circulating tumor cells from breast cancer patients that initiates metastasis in a xenograft assay. Nat Biotechnol. 2013; 31: 539-544.

40. Khanna $\mathrm{C}$, Hunter $\mathrm{K}$. Modeling metastasis in vivo. Carcinogenesis. 2005; 26: 513-523.

41. Richmond A, Su Y. Mouse xenograft models vs GEM models for human cancer therapeutics. Dis Model Mech. 1: 78-82.
42. Francia G, Cruz-Munoz W, Man S, Xu P, Kerbel RS. Mouse models of advanced spontaneous metastasis for experimental therapeutics. Nat Rev Cancer. 2011; 11: 135-141.

43. Rack B, Schindlbeck C, Jückstock J, Andergassen U, Hepp P, Zwingers T, Friedl TWP, Lorenz R, Tesch H, Fasching PA, Fehm T, Schneeweiss A, Lichtenegger W, et al. Circulating tumor cells predict survival in early average-to-high risk breast cancer patients. J Natl Cancer Inst. 2014; 106.

44. Janni WJ, Rack B, Terstappen LWMM, Pierga J-Y, Taran F-A, Fehm T, Hall C, de Groot MR, Bidard F-C, Friedl TWP, Fasching PA, Brucker SY, Pantel K, et al. Pooled Analysis of the Prognostic Relevance of Circulating Tumor Cells in Primary Breast Cancer. Clin Cancer Res. 2016; 22: 2583-2593.

45. Horoszewicz JS, Leong SS, Chu TM, Wajsman ZL, Friedman M, Papsidero L, Kim U, Chai LS, Kakati S, Arya SK, Sandberg AA. The LNCaP cell line--a new model for studies on human prostatic carcinoma. Prog Clin Biol Res. 1980; 37: 115-132.

46. Kozlowski JM, Fidler IJ, Campbell D, Xu ZL, Kaighn ME, Hart IR. Metastatic behavior of human tumor cell lines grown in the nude mouse. Cancer Res. 1984; 44: $3522-3529$.

47. Thalmann GN, Anezinis PE, Chang SM, Zhau HE, Kim EE, Hopwood VL, Pathak S, von Eschenbach AC, Chung LW. Androgen-independent cancer progression and bone metastasis in the LNCaP model of human prostate cancer. Cancer Res. 1994; 54: 2577-2581.

48. Kaighn ME, Narayan KS, Ohnuki Y, Lechner JF, Jones LW. Establishment and characterization of a human prostatic carcinoma cell line (PC-3). Invest Urol. 1979; 17: 16-23.

49. Price JE, Polyzos A, Zhang RD, Daniels LM. Tumorigenicity and metastasis of human breast carcinoma cell lines in nude mice. Cancer Res. 1990; 50: 717-721.

50. Scherer WF, Syverton JT, Gey GO. Studies on the propagation in vitro of poliomyelitis viruses. IV. Viral multiplication in a stable strain of human malignant epithelial cells (strain HeLa) derived from an epidermoid carcinoma of the cervix. J Exp Med. 1953; 97: 695-710.

51. Pfaffl M. Quantification strategies in real-time PCR Michael W. Pfaffl. In: Bustin SA, editor. A-Z of quantitative PCR. 1st ed. La Jolia: International University Line (IUL); 2004. p. 87-112.

52. Lowes LE, Hedley BD, Keeney M, Allan AL. Adaptation of semiautomated circulating tumor cell (CTC) assays for clinical and preclinical research applications. J Vis Exp. 2014; : e51248.

53. Thalmann GN, Sikes RA, Wu TT, Degeorges A, Chang SM, Ozen M, Pathak S, Chung LWK. LNCaP progression model of human prostate cancer: Androgen-independence and osseous metastasis. Prostate. 2000; 44: 91-103.

54. Valta MP, Tuomela J, Vuorikoski H, Loponen N, Väänänen RM, Pettersson K, Väänänen HK, Härkönen PL. FGF-8b induces growth and rich vascularization in an orthotopic PC-3 model of prostate cancer. J Cell Biochem. 2009; 107: 769-784. 